Anales de Geografía de la Universidad Complutense ISSN: 0211-9803

http://dx.doi.org/10.5209/AGUC.57727

\title{
Organización e impacto territorial de la actividad pesquera comercial ribereña en la Reserva de la Biosfera Ría Celestún (México) ${ }^{1}$
}

\author{
José Manuel Crespo Guerrero²; Araceli Jiménez Pelcastre ${ }^{3}$ \\ Recibido: 9 de septiembre del 2016 / Enviado a evaluar: 28 de febrero del 2017 / Aceptado: 24 de mayo del 2017
}

Resumen. La pesca comercial ribereña es una práctica económica común para las poblaciones que viven en las áreas naturales protegidas de dominio marítimo-terrestres. El presente trabajo tiene como objetivo describir la forma organizativa de la pesca comercial ribereña en la Reserva de la biosfera de Ría Celestún (noroeste de la península mexicana de Yucatán). Se mostrará cómo la organización y la regulación oficial de la actividad se completan con una distribución de los espacios de aprovechamiento de naturaleza sociocultural que están siendo modificados por la demanda de los mercados internacionales (asiático, europeo y estadounidense). Para ello, se utilizarán datos cuantitativos procedentes de las instituciones públicas y entidades privadas, y cualitativos obtenidos en el trabajo de campo.

Palabras clave: Áreas naturales protegidas; geografía económica; globalización; pesca; Yucatán.

\section{[en] Organization and territorial impact of coastal commercial fishing in the Ría Celestún Biosphere Reserve (Mexico)}

\begin{abstract}
Coastal commercial fishing is a common economic practice for local populations of natural protected areas which encompass both maritime and terrestrial environments. The aim of this paper is to describe the organizational pattern of coastal commercial fishing in the Ría Celestún Biosphere Reserve (northeast of the Yucatan peninsula). It explains how the organization and official regulations of the above-mentioned activity are completed by the distribution of spaces of utilization, which is embedded in its socio-cultural context, and is currently being modified by the demand conditions of international markets (US, European and Asian). The research is based on quantitative data provided by public institutions and private entities, as well as on qualitative data obtained during the field work.
\end{abstract}

Key words: Natural protected areas; economic geography; globalization; fishing; Yucatan

1 Investigación realizada gracias al Programa UNAM-DGAPA-PAPIIT. Clave IA300716. Organización del sector pesquero comercial ribereño en las áreas naturales protegidas del estado de Campeche.

2 Departamento de Geografía Económica. Instituto de Geografía. Universidad Nacional Autónoma de México.

E-mail: jcrespo@igg.unam.mx

3 Instituto de Ciencias Sociales y Humanidades. Universidad Autónoma del Estado de Hidalgo (México).

E-mail: aracelijip@hotmail.com 


\section{[fr] Organisation et impact territorial de l'activité de pêche commerciale côtière dans la Reserve de la biosphère Ría Celestún (Mexique)}

Résumé. La pêche commerciale côtière est une pratique économique commune aux populations qui habitent dans les aires naturelles protégées de domaine maritimo-terrestre. Ce travail a pour but de décrire la façon dont s'organise la pêche commerciale côtière dans la Réserve de la biosphère de Ria Celestún (nord-ouest de la péninsule mexicaine du Yucatán). Nous montrerons comment l'organisation et la régulation officielle de l'activité vont de paire avec une distribution des espaces d'exploitation de nature socioculturelle qui sont en voie de modification suivant la demande des marchés internationaux (asiatique, européen et américain). À cet effet nous utiliserons des données quantitatives provenant des institutions publiques et privées, notre travail sur le terrain nous ayant fourni les données qualitatives.

Mots clés: Aires naturelles protégées ; géographie économique ; mondialisation ; pêche ; Yucatán

Cómo citar. Crespo Guerrero, J.M. y Jiménez Pelcastre, A. (2017): Organización e impacto territorial de la actividad pesquera comercial ribereña en la Reserva de la Biosfera Ría Celestún (México). Anales de Geografía de la Universidad Complutense, 37(2), 297-324.

Sumario. 1. Introducción. 2. Materiales y métodos. 3. Las áreas naturales protegidas de México: El significado de la Reserva de la Biosfera Ría Celestún. 4. Organización de la actividad pesquera en Isla Arena y Celestún. 5. Impacto territorial de los mercados internacionales en la actividad pesquera. 6. Conclusiones. 7. Referencias bibliográficas.

\section{Introducción}

En castellano, la palabra "pesca" posee una destacada dimensión polisémica de tal forma que puede significar el oficio, el arte de practicarla, el aprovechamiento y evidentemente, la acción y el efecto de pescar. También es una actividad económica primaria que se practica en diferentes cuerpos de agua ya sean oceánicos o continentales, con la intención de obtener comestibles frescos y materias primas que abastezcan al sector secundario.

La práctica de la pesca se remonta a los orígenes de la humanidad y los variados productos a los que da acceso están ligados a aspectos geográficos, técnicos y culturales. La pesca, entendida como aprovechamiento, es un recurso natural renovable claro está, siempre y cuando su tasa de regeneración sea respetada. En este sentido, resulta pertinente reconocer que los océanos no son una fuente inagotable de recursos y un adecuado manejo de la actividad haliéutica es fundamental para asegurar su continuidad. Esta práctica posee una dimensión territorial, histórica y cultural, que ha motivado la creación de ambientes, fruto de la conjunción entre el medio natural y su manejo. Ciertas legislaciones de protección de la naturaleza los han reconocido por medio de una nueva generación de categorías de áreas naturales. Éstas no sólo consideran los valores ambientales que ofrecen determinados ecosistemas, sino también las prácticas culturales, como es el caso de las actividades económicas.

La geografía permite estudiar el alcance de la globalización en los flujos comerciales de materias primas. La irrupción de mercados emplazados a miles de 
kilómetros de las zonas con recursos naturales, ha modificado o reemplazado prácticas artesanales por otras de alcance industrial y también ha introducido cambios en la organización económica, por tanto ha impactado territorialmente: claro ejemplo de ello lo muestra la actividad pesquera. Los países demandantes de recursos naturales sobre zonas que habían estado al margen de cualquier interés económico más allá del local y que habían sido catalogadas bajo alguna figura de protección ambiental, han puesto a prueba el peso real de las herramientas de gestión vinculadas a las áreas naturales protegidas (ANP).

Hoy, la producción pesquera de captura marina en México asciende a 1.396.205 t, lo que representa el 1,7\% de la producción mundial. El promedio mexicano de 2003 a 2012 fue de $1.352 .000 \mathrm{t}$, cifra que lo situó entre los 20 primeros países productores del mundo (FAO, 2016). La mirada económica hacia el mar no es nueva, entre $1940 \mathrm{y}$ 1970 la producción mexicana tuvo un crecimiento constante y alcanzó un volumen de captura superior a las $270.000 \mathrm{t}$ anuales; en la siguiente década llegó a $1.058 .000 \mathrm{t}$, esto significa que se incrementó en un $380 \%$, plazo realmente corto. México dispone de 76.096 embarcaciones activas de pesca, el 97\% de la flota es de tipo menor (no supera los 10,5 $\mathrm{m}$ de eslora), característica obligada para la práctica de la pesca a pequeña escala. Desde 1980 hasta 2012, la flota de pequeñas embarcaciones activas se ha incrementado un 55\% y ha pasado de 32.150 a 74.055 (SAGARPA, 2013), ello representa un promedio anual de 1.309 unidades. Las autoridades mexicanas han constatado en sus aguas sobre-explotación pesquera, de ahí la importancia de un adecuado ordenamiento de la actividad (FAO, 2010).

La legislación ambiental de México define figuras de protección de la naturaleza que permiten e incluso promueven sectores económicos (siempre y cuando respeten los objetivos marcados en sus herramientas de manejo). Las categorías de protección se asocian a instrumentos de gestión de los recursos naturales que garantizan los servicios que proporcionan los ecosistemas (EUROPARC-España, 2008). Es decir, por un lado, velan por la conservación de las funciones ecológicas, la supervivencia de ciertas especies, la preservación de elementos abióticos o la recuperación de ecosistemas y por otro, contribuyen a mejorar el nivel de desarrollo socioeconómico de las poblaciones que viven en contacto con estos espacios (Araque y Crespo, 2009).

Sabido es que el éxito de un ANP no proviene de su mera declaración, sino por alcanzar los objetivos expresados en sus instrumentos de planeación (Crespo y Peyroti, 2016), por lo que es esencial la capacidad de gestión o manejo (Carabias et al., 2003; Hockings et al., 2000). Ésta se sustenta en varios pilares: la gobernabilidad (marco legal y acción política), la implicación social (participación y apoyo de las comunidades locales, propietarios y otros grupos sociales), los instrumentos de planificación (planes estratégicos y planes ejecutivos) y los recursos (humanos, económicos, de conocimiento e infraestructuras). Cuando un ANP no inicia el camino para lograr la finalidad por la que se creó, se la denomina «parque de papel» (Rife et al., 2013).

Este artículo contribuye a incrementar los escasos trabajos científicos que consideran la pesca comercial ribereña en México bajo una perspectiva territorial. En 
esta mirada de análisis destacan los geógrafos Sánchez Crispín y Villerías Salinas (2010) cuyas investigaciones se han desarrollado en las costas del estado de Guerrero. Otras aportaciones desde la geografía son: el "Atlas de procesos territoriales de Yucatán" (Sánchez-Salazar et al., 1999) y "Usos de Sistemas de Información Geográfica en pesquerías: la pesca en Yucatán, al sur del Golfo de México" (Mexicano-Cintora et al. 2009). En la última década, las ciencias sociales que trabajan los aspectos costeros y marinos yucatecos, están investigando sobre la conflictividad producida por el control de los recursos naturales (Robles de Benito, 2005; Soares et al. 2014; Uc; 2007; Viga; 2007, Morales, 2015) y la vulnerabilidad socio-ambiental (Gutiérrez, 2014; Soares y Velázquez, 2011). La antropología en su vertiente social, es la ciencia que más ha aportado al estudio de los pescadores yucatecos: en esta línea podemos considerar los trabajos "Los pescadores de la laguna de Términos" de Rodriguez y Melville (1984) y "Los pescadores de la península de Yucatán" de Chenaut (1985) como dos de los precursores. La antropóloga Julia Elena Fraga (2004; 2009) es la investigadora que más se ha dedicado al estudio de este tema.

En la primera parte del artículo nos centramos en la definición de aspectos puramente metodológicos que incluyen la descripción de la bibliografía consultada y las herramientas de trabajo; a continuación, nos interrogamos sobre el alcance de la categoría de conservación "reserva de la biosfera" y el significado legal de la pesca comercial ribereña. Posteriormente, analizaremos la organización del mencionado sector pesquero en Isla Arena y Celestún, únicas localidades enclavadas en la línea de costa de la Reserva de la biosfera Ría Celestún. Acto seguido, responderemos a la siguiente interrogante ¿de qué manera la demanda internacional de ciertos productos del mar está transformando la actividad pesquera e impactando en el territorio de la reserva?

\section{Materiales y métodos}

Los materiales tratados en el artículo resultaron del trabajo de gabinete y de campo. El necesario repaso a la bibliografía nos acercó a textos de diversa naturaleza: los legales nos aproximaron al marco legislativo de la actividad haliéutica y la terminología que utilizan las distintas administraciones públicas mexicanas; los institucionales, nos ofrecieron informes con datos económicos y ambientales; los científicos, información de los estudios realizados desde las ciencias sociales y sobre la pesca comercial ribereña en la Reserva de la biosfera Ría Celestún (RBRC); no dejemos en el tintero los artículos periodísticos que nos proporcionaron una rica información sobre la actualidad pesquera, a menudo de carácter conflictivo.

Consideramos imprescindible una salida de campo para actualizar y contrastar la información de las fuentes escritas y mediante la observación y la interrelación con los diferentes sujetos, dar profundidad al estudio. Identificamos a los actores que nos podían proporcionar mayor riqueza informativa y cumplir con uno de nuestros objetivos metodológicos: la polifonía. Así, diseñamos dos guías para realizar entrevistas: la primera, semiestructurada, contenía preguntas cerradas y abiertas, 
además de material para los pescadores ribereños con el fin de que elaborasen una cartografía especializada; su duración debía rondar los 30 minutos. La segunda guía, no estructurada, sirvió de base para entrevistar a los responsables gubernamentales, los gerentes de las cooperativas pesqueras, los empresarios y los directores de las asociaciones de pescadores; su extensión duraría entre los 60 y los 90 minutos.

Las entrevistas semiestructuradas se organizaron en cinco bloques temáticos y un anexo: datos personales del pescador (información relativa al sexo, lugar de nacimiento, edad, residencia, estado civil, estudios finalizados y aspectos sobre el núcleo familiar); oficio de la pesca (motivos de elección de la pesca como actividad laboral, meses destinados al trabajo en el mar, gastos asociados a una jornada, ganancia, distribución de los beneficios y modelo de asociación legal para la práctica pesquera); aspectos técnicos (métodos, recursos y tecnificación); el arte de la pesca y los espacios de producción, almacenaje y comercialización (especies haliéuticas, lugar, distancia y tiempo para acceder a las zonas de pesca; empacado, distribución y centros de compraventa); influencia del ANP en la actividad pesquera (información sobre posibles cambios promovidos por los instrumentos de manejo); y un anexo para la elaboración de la cartografía. Las entrevistas no estructuradas fueron abiertas y trataron aspectos relativos al perfil de cada sujeto y sus responsabilidades en la pesca.

Una vez diseñadas las herramientas principales del trabajo de campo y concretadas las entrevistas con las instituciones públicas, las empresas privadas, las cooperativas y las asociaciones pesqueras más representativas, realizamos la salida entre el 16 y el 30 de marzo de 2016 a Campeche y Yucatán (la RBRC se emplaza entre ambos estados mexicanos). Registramos 48 entrevistas: 21 en Isla Arena, 23 en Celestún; y dos en cada una de las ciudades capitales de los estados, San Francisco de Campeche y Mérida. Hubo otras tantas conversaciones informales que si bien no fueron cuantificadas, enriquecieron nuestra praxis.

Con el fin de conseguir relevancia social, interactuamos con los actores del sector en sus espacios de trabajo y residencia; es pertinente señalar que al entrevistar a los pescadores de Isla Arena y Celestún, siempre se les garantizamos el anonimato. Nos reunimos con los responsables de dos cooperativas pesqueras (una por cada localidad). La empresa Hulkin S.A. de C.V., la más importante de la reserva, nos concedió una reunión con su responsable de ventas. Entrevistamos a cinco representantes de instituciones públicas: en San Francisco de Campeche nos reunimos con el subdelegado y el jefe de departamento de la oficina de la Comisión Nacional de Acuacultura y Pesca (CONAPESCA) del estado de Campeche; en Mérida, con el subdirector de la CONAPESCA en Yucatán y el jefe de departamento de la RBRC. Conversamos con una representante de la municipalidad de Celestún y el presidente del Comité Náutico de aquella localidad.

Realizamos el análisis de la información mediante un procedimiento inductivo que consideró las respuestas a nuestras preguntas; su selección se realizó atendiendo a la estructuración de los ejes temáticos diseñados (Strauss y Corbin, 2002). Gracias a los datos recabados de las entrevistas y las observaciones, conocimos la organización de la actividad pesquera, los procesos económicos que se desarrollan y la experiencia de 
las personas que la practican. También conseguimos información sobre los impactos, transformaciones y tensiones en torno al sector de la pesca a pequeña escala. Los datos cuantitativos (número de permisos, personas físicas y morales del sector, capturas, entre otros) fueron aportados en su mayoría por los responsables de las instituciones públicas.

Revisamos la cartografía de la localización y la zonificación del ANP. Para facilitar el análisis territorial, emprendimos diversos procedimientos metodológicos a fin de plasmar en la cartografía especializada los datos cualitativos obtenidos en el trabajo de campo (en ocasiones fue triangulada con información cuantitativa). De tal forma que identificamos los procesos de distribución de los espacios de pesca y sus estructuras resultantes, reflejo de la organización territorial de la actividad. Nuestra investigación quedó fundamentada por los datos cuantitativos y cualitativos, su análisis y expresión cartográfica.

\section{Las áreas naturales protegidas de México: El significado de la Reserva de la Biosfera Ría Celestún}

La Ley General de Equilibrio Ecológico y Protección del Ambiente (LGEEPA; DOF, 2016) define las ANP en México y distingue seis categorías federales de protección: Parque nacional, Reserva de la biosfera, Área de protección de flora y fauna, Santuario, Área de protección de recursos naturales y Monumento natural. Todas disponen de un Programa de Manejo (PM) "instrumento rector de planeación y regulación que establece actividades, acciones y lineamientos básicos para la operación y administración del ANP [...]”. Por mandato legal, cada PM estará aprobado a más tardar un año después de publicar su declaración en el Diario Oficial de la Federación (DOF) y será revisado "por lo menos cada cinco años, con el objeto de evaluar su efectividad y proponer posibles modificaciones" (DOF, 2014: 24).

La figura de protección más frecuente es la de Parque nacional, mientras que la categoría con más superficie es la de Reserva de la biosfera: representa casi la mitad de la extensión de las ANP federales. La Comisión Nacional de Áreas Naturales Protegidas (CONANP) reconoce 177 ANP de jurisdicción federal que abarcan una extensión de 25.628.230 ha (Tabla 1). De éstas, 69 protegen ecosistemas marinos y litorales, 36 son exclusivamente marinas. Las ANP federales mexicanas representan el $10,57 \%$ de la superficie terrestre y el $1,54 \%$ del mar territorial (franja de mar adyacente al continente e islas, que se extiende hasta las 12 millas náuticas hacia su interior desde la línea de costa). 
Tabla 1. Áreas naturales protegidas federales de México en octubre de 2016.

\begin{tabular}{lcc}
\hline \multicolumn{1}{c}{ Categoría de Protección } & Número de ANP & Superficie en ha \\
\hline Parque nacional & 66 & 1.411 .319 \\
Reserva de la biosfera & 41 & 12.751 .149 \\
Área de protección de flora y fauna & 39 & 6.795 .963 \\
Santuario & 18 & 150.193 \\
Área de protección de recursos naturales & 8 & 4.503 .345 \\
Monumento natural & 5 & 16.269 \\
Total & 177 & 25.628 .238 \\
\hline
\end{tabular}

Fuente: Elaborado con base en CONANP (2016).

Como toda ANP, las reservas de la biosfera disponen de una zonificación interna. En las zonas núcleo, sólo están permitidas actividades de preservación de ecosistemas y educación ambiental y se prohíbe realizar cualquier tipo de aprovechamiento que modifique las funciones econsistémicas; por tal razón, en aquéllas de naturaleza marina, debe restringirse el tráfico de embarcaciones de conformidad con el PM. Mientras en las zonas de amortiguamiento, únicamente pueden desarrollarse actividades productivas tradicionales, que deben ser estrictamente compatibles con los objetivos de los programas de ordenamiento ecológico, planeación y aprovechamiento sustentable.

En octubre de 2016, México disponía de 14 reservas de la biosfera de tipo marino y marítimo-terrestre, que en conjunto ocupaban una extensión en el mar de 3.069.120,29 ha, es decir, el 29\% de la superficie total protegida por dicha categoría. La superficie media terrestre de una reserva en el país alcanzaba las 311.000 ha y el área media marina protegida las 220.000 ha. La reserva con mayor extensión marina era la de Islas Marías -océano Pacífico, estado de Nayarit- con 616.989,57 ha y la de menor superficie, precisamente, Ría Celestún con 19.555,76 ha -golfo de México, estados de Campeche y Yucatán- (Gráfico 1).

Gráfico 1. Información relativa a la figura de protección Reserva de la biosfera en México

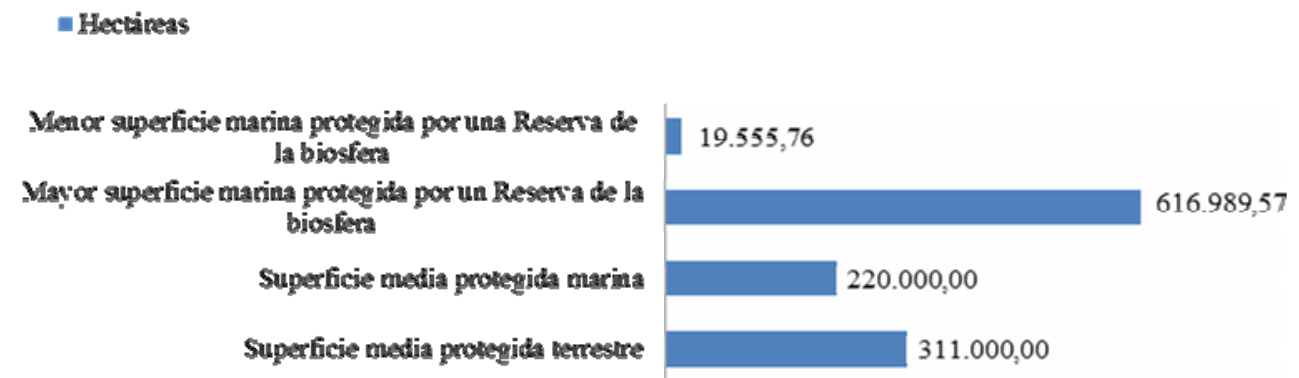

Fuente: elaborado con base en CONANP (2016). 
La RBRC, situada al noroeste de la península de Yucatán (Figura 1), comprende una superficie total de $81.492,33$ ha (el $24 \%$ es marino). Se extiende por los municipios de Celestún, Maxcanú, Halachó, Hunucmá -en el estado de Yucatán- y Calkiní -en el estado de Campeche-. En la RBRC, únicamente hay dos localidades costeras: Isla Arena (municipio de Calkiní) y Celestún. Su decreto de creación es del 27 de noviembre del 2000 y su PM se publicó dos años después. Pero aún no se ha actualizado.

Figura 1. Localización de la Reserva de la biosfera Ría Celestún, 2016

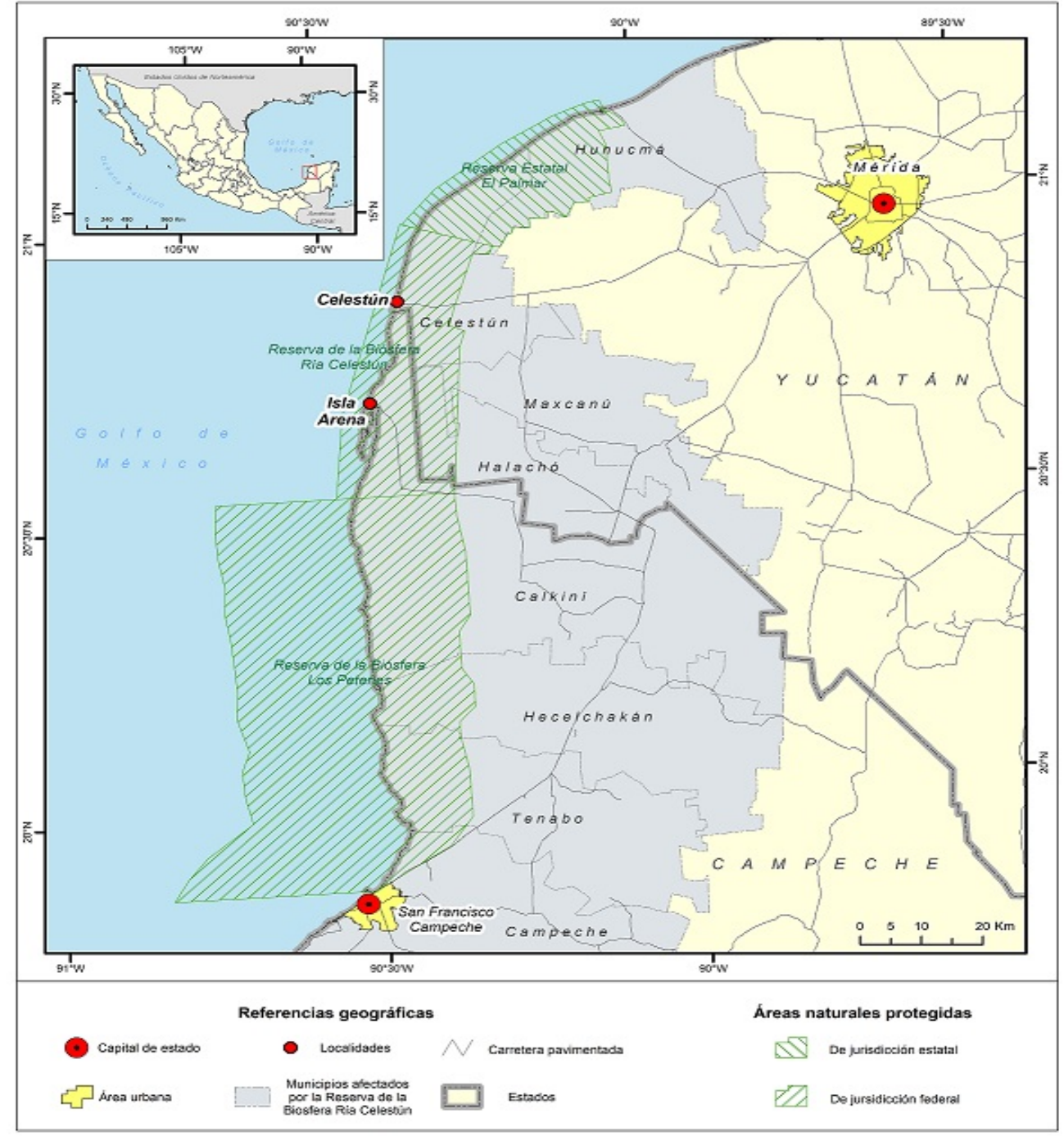

Fuente: Elaborado con base en CONANP, 2016. Cartografía, José-Alberto Garibay-Gómez. 
La RBRC es considerada de tamaño pequeño pues de entre las 41 reservas mexicanas, ocupa la posición 30; es cuatro veces menor que la superficie media del resto de las reservas. Sin embargo, este hecho hay que relativizarlo al formar parte de un sitio prioritario marino para la conservación de la biodiversidad -catalogado de gran importancia- constituido por otras dos ANP colindantes (CONABIO, 2008). Al norte, se localiza la Reserva estatal "El Palmar" (Yucatán) con una extensión de 49.605,39 ha (casi el 19\% en el mar) y al sur, en el estado de Campeche, se emplaza la Reserva de la biosfera "Los Petenes" que abraza una superficie de 282.857,62 ha (el $36 \%$ en las aguas del golfo de México). El corredor se extiende por unas 414.000 ha (CONANP, 2016).

Figura 2. Zonificación de la Reserva de la biosfera Ría Celestún, 2016

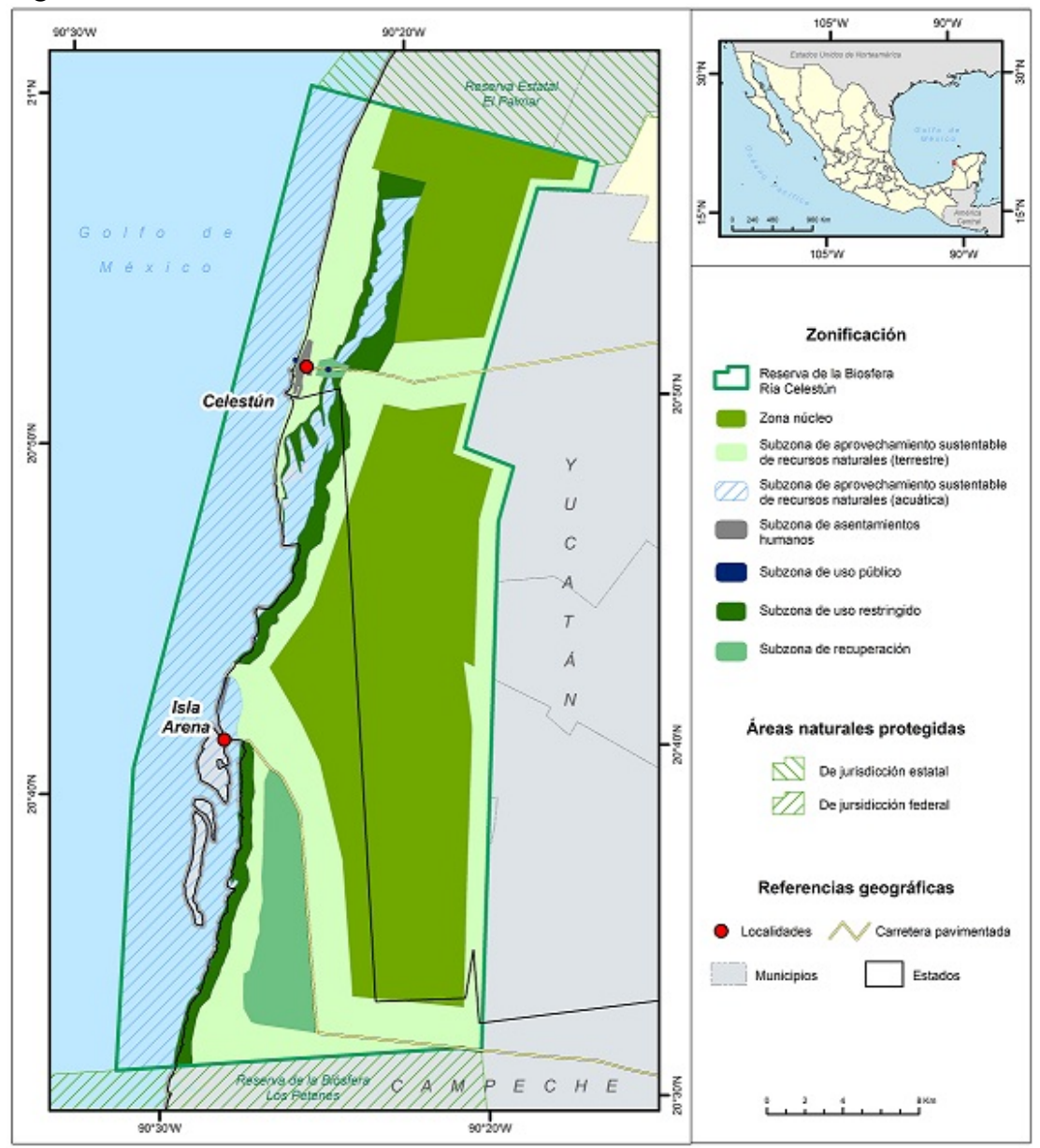

Fuente: Elaborado con base en CONANP, 2016. Cartografía, José-Alberto Garibay-Gómez. 
Mencionado sitio prioritario marino integra una región ecológica caracterizada por la diversidad de ambientes: manglares, petenes, vegetación de duna costera, sabana y selva baja inundable, todo ello en un excelente estado de conservación. Las tres ANP están reconocidas internacionalmente como sitio Ramsar (en ellas se ubica parte de la desembocadura de la cuenca noroccidental del agua subterránea de la península de Yucatán) y desde 2004, la RBRC pertenece al programa Hombre y Biosfera de la Unesco. La RBRC preserva una de las áreas de manglar más extensas del golfo de México donde viven 107 especies de peces, 104 de malacofauna, 77 aves, 33 mamíferos y cinco reptiles. Como dato peculiar, la ría Celestún es un lugar de descanso y reproducción de un importante número de aves migratorias, entre las que destaca el flamenco rosado.

La reserva (Figura 2) se organiza en dos zonas núcleo que representan el 37,18\% del ANP (30.291,18 ha) y una zona de amortiguamiento que incorpora el restante $62,82 \%$ (poco más de 51.000 ha). Las zonas núcleo abarcan la mayor parte de la superficie de manglar y los petenes -principales suministradores de agua dulce del sistema estuario-; por consiguiente, sólo están permitidas la investigación científica y la educación ambiental. La zona de amortiguamiento se divide en 5 subzonas: de aprovechamiento sustentable de los recursos naturales, uso restringido, asentamientos humanos, uso público y recuperación. Nos interesa la primera subzona porque afecta a toda la superficie acuática; en ella, los pobladores de Isla Arena y Celestún aprovechan, mediante un uso controlado, los recursos haliéuticos y salinos. También emprenden actividades ecoturísticas (SEMARNAT, 2010). Paradójicamente, casi toda la actividad pesquera comercial ribereña de aquellas localidades se realiza en aguas contiguas al ANP, si bien dentro de la región marina prioritaria.

\section{Organización de la actividad pesquera en Isla Arena y Celestún}

La Ley General de Pesca y Acuacultura Sustentable (LGPAS) de 1992, modificada en 2001 y el Reglamento de la Pesca (1999) constituyen el marco legal fundamental que gobierna la conservación, la preservación, la explotación y el manejo de toda la flora y fauna acuática (FAO, 2016b). Las Normas Oficiales Mexicanas (NOM) implementan la LGPAS, de tal forma que pormenorizan los requisitos para la realización y el desarrollo de la pesca y la acuacultura. Las actuaciones de las NOM son propuestas por las secretarías administrativas con reconocimiento de jurisdicción.

La Secretaría de Agricultura, Ganadería, Desarrollo Rural, Pesca y Alimentación (SAGARPA) es quien administra la legislación de las pesquerías y la acuacultura. Mientras su entidad, la CONAPESCA, es responsable del manejo, coordinación y desarrollo de las políticas de uso y explotación sostenible de las pesquerías y los recursos acuáticos. El Instituto Nacional de Pesca (INP) que también es dependiente de la SAGARPA, investiga y asesora a la CONAPESCA sobre la preservación, repoblación, promoción, cultivo y desarrollo de especies acuáticas. El INP dispone de un instrumento para el manejo de pesquerías: la Carta Nacional Pesquera (inventario 
y resumen actualizado anualmente de los recursos pesqueros en los cuerpos de agua federales).

La LGPAS (DOF, 2007) considera la actividad pesquera como "el acto de extraer, capturar o recolectar, por cualquier método o procedimiento, especies biológicas o elementos biogénicos, cuyo medio de vida total, parcial o temporal, sea el agua" (LGPAS, art. $4^{\circ} . \mathrm{XXVII}$ ). Según la finalidad de la pesca, la ley diferencia entre varios tipos: deportivo, comercial, didáctico, consumo directo $\mathrm{y}$ fomento. La pesca comercial tiene propósitos económicos y presenta múltiples expresiones en función de su organización legal, artes empleadas, especies y cantidad de captura, número de pescadores por embarcación, etc. Con el fin de simplificar la expresión administrativa de la pesca comercial, la SAGARPA toma como referencia el tamaño de la embarcación y así distingue entre la pesca de altura y la ribereña. Esta última es la actividad de extracción de recursos acuáticos practicada con embarcaciones menores (eslora total máxima de $10,5 \mathrm{~m}$ ), con o sin motor fueraborda, con o sin sistema de conservación a base de hielo y con una autonomía máxima de tres días (LGPAS, art. $4^{\circ}$. XVII).

La modalidad de pesca que nos ocupa es la comercial ribereña que en el ámbito internacional está inserta en la denominada pesca en pequeña escala (FAO, 2011). Aunque no dispone de una definición universal, diversos países emplean el término para referirse a una modalidad haliéutica que se caracteriza por usar un determinado tipo de embarcación, la utilización o no de motor, la modalidad de captura, el tiempo dedicado a las faenas, los conocimientos empleados, la tecnología desarrollada y estar siempre emprendida sobre la plataforma continental.

Para entender la organización de la actividad pesquera comercial ribereña en la RBRC consideraremos la población activa, el número de pescadores, las unidades económicas (por sector: social o privado), el número de embarcaciones, las capturas y los mercados de venta.

Los pescadores deben estar organizados legalmente para realizar su actividad laboral y también acceder a los programas de apoyo de los diferentes gobiernos: de adquisición de activos productivos (sustitución de motores fueraborda; modernización de embarcaciones; proyectos de inversión, etc.); de vigilancia de los recursos pesqueros y acuícolas; de compra de combustible; y de empleo temporal para asistir a cursos de formación durante los periodos de baja producción pesquera. Hay diversas maneras para constituirse legalmente: desde la esfera privada, empresas o permisionarios; desde el sector social, sociedades cooperativas, sociedades de producción rural, sociedades de solidaridad social y uniones de pescadores.

Como apuntamos al inicio, Isla Arena y Celestún son las dos únicas localidades de la RBRC y son eminentemente pesqueras. Isla Arena tiene tan solo 754 habitantes y Celestún 6.810. Según los últimos datos oficiales de 2010 (INEGI), la población empleada en Isla Arena alcanzaba los 242 trabajadores (231 pertenecen a la población masculina y sólo 11 a la femenina). Prácticamente, toda la población ocupada se dedica al sector de la pesca comercial ribereña, pues no está censada ninguna embarcación mayor. En la actualidad, hay 286 lanchas registradas que representan el 
$7,6 \%$ de las 3.776 embarcaciones activas menores del estado de Campeche. En 2015, la CONAPESCA estimó en 568 el número de pescadores con base en el puerto de Isla Arena. Dicha cifra supera al número total de empleados de la localidad, en parte por el desfase cronológico de recolecta de datos, la diferente metodología empleada y también porque incorpora a los pescadores que viven en localidades limítrofes (San Nicolás, Santa Cruz, Tankuché y Santa María) y que se desplazan para complementar sus rentas.

En Isla Arena la forma más habitual de organización de los pescadores es la de persona física con permiso de pesca y equipo. Esta figura agrupa a los pescadores libres -pescan en sus propias embarcaciones- y a los llamados permisionarios empresarios que normalmente no pescan y contratan a trabajadores que no disponen de permisos ni equipos, conocidos como pescadores apatronados o jornaleros-. Administrativamente la palabra permisionario se refiere a toda persona, física o moral, con permiso de pesca. Isla Arena registra 126 personas físicas dedicadas a la pesca (Figura 3). Casi todos, salvo una decena, tienen una embarcación (SENASICA, 2016); por lo tanto, predominan los pescadores libres. También se presentan personas morales, como las sociedades cooperativas de producción pesquera, las 10 cooperativas de Isla Arena cuentan con un total de 150 lanchas; ocho de ellas emplean entre 11 y 30 trabajadores y dos entre 31 y 50 (Figura 3). Un hecho importante es que el estado de Campeche privilegia a las cooperativas en los programas de apoyo para la adquisición de activos productivos y en la compra de combustibles. Ninguna sociedad anónima dedicada a la pesca está registrada en la localidad isleña.

Existe una tercera figura al borde de la ilegalidad: los matriculados, matriculaos o matriculeros ${ }^{4}$. Se trata de pescadores que teniendo matriculada su embarcación en la capitanía marítima, no poseen licencia de pesca. La autoridad federal, representada en la CONAPESCA, y siguiendo las directrices de la Carta Nacional Pesquera, no concede más permisos. Con el fin de solventar esta situación, el estado de Campeche llegó a un arreglo con las autoridades federales para que los matriculados pudieran ejercer la actividad haliéutica sólo en aguas campechanas. Se estima en medio centenar el registro de este tipo de pescadores ribereños (Figura 3).

Celestún es el centro productivo de pescado más importante de la RBRC. Enclavado en el estado de Yucatán, posee una población empleada activa de 2.648 trabajadores -2.101 hombres y 547 mujeres- (INEGI, 2010). El censo de pescadores de la localidad es de 1.670 , esto significa que el $63 \%$ de la población empleada se dedica a la pesca.

En el municipio de Celestún, el 58,14\% de la población participa en el sector primario, donde sobresale la pesca. El sector secundario absorbe al $28,12 \%$ de la

\footnotetext{
${ }^{4}$ Esta acepción que algunos miembros de este colectivo utilizan para autodenominarse, tiene una connotación claramente jocosa: "matri-culero". El término refleja lo incómodo que dicho grupo resulta a la administración pues ésta tolera que pesque sin permiso, lo que se reconoce como un triunfo por aquellos pescadores.
} 
población empleada activa, que fundamentalmente se dedica al primer procesamiento y empacado de la producción pesquera. El sector terciario ocupa el 13,36\% impulsado por el turismo gracias a la creación de la reserva, la valorización del recurso territorial de los flamencos rosados y los paseos turísticos por la ría en pequeñas embarcaciones.

En marzo de 2016, según datos de la CONAPESCA, había 59 unidades económicas físicas y 21 unidades económicas morales registradas. De éstas, 18 eran sociedades cooperativas de responsabilidad limitada de capital variable, dos sociedades anónimas de capital variable y una sociedad anónima limitada. Desde hace más de cuatro décadas, Celestún cuenta con la única fábrica de hielo y el único centro de abastecimiento de gasolina del ANP.

El censo de embarcaciones menores activas de 2016 contabilizó en Celestún unas 500 unidades; si éstas se relacionan con los permisos de pesca por especie (una embarcación puede disponer de varios permisos) su número se eleva a 832 , lo que representa una cuarta parte del esfuerzo pesquero del estado de Yucatán. El 60\% de las embarcaciones inscritas en el registro celestunero está en manos de personas físicas; el $24 \%$ lo controlan las empresas privadas y las cooperativas el $16 \%$. Si relacionamos las embarcaciones por recurso pesquero, los porcentajes varían levemente: las 59 unidades económicas físicas poseen el $55 \%$ de los permisos pesqueros, las sociedades anónimas el $27 \%$ y las sociedades cooperativas el $18 \%$.

Las personas físicas con mayor número de permisos de pesca por embarcación, nombradas por su acrónimo, son MRS (121) y AGY (45): son auténticos empresarios. La cooperativa pesquera con más permisos es Delfines de Celestún (30). Y en el lado empresarial despuntan Hulkin (121), PEYUCSA (68) y Pescados y Mariscos de Celestún (36). Es decir, estas seis unidades económicas poseen la mitad de los permisos por embarcación de Celestún y controlan gran parte de los procesos productivos del resto de las unidades económicas.

MRS es el permisionario más importante de la RBRC por el número de trabajadores contratados directamente, entre 11 y 30 . Pero de entre todas las unidades económicas del sector privado de Celestún, destaca Hulkin, empresa de capital hispano-mexicano que inició sus actividades en 1986 y que actualmente emplea de manera directa a 40 trabajadores repartidos entre las áreas de administración, recepción del pescado, procesado, embalaje y distribución. El salario de los pescadores que trabajan para Hulkin depende de la ganancia del día y se calcula así: si salieron tres pescadores en una lancha, la ganancia del día, menos los gastos de la jornada laboral (gasolina, hielo, carnada y alimentación), se divide entre cuatro, o sea, los tres pescadores y la propietaria de la embarcación (Hulkin). El precio del producto lo estipula la empresa y cuando los mercados internacionales demandan una producción superior a las capturas de los pescadores contratados por Hulkin, la empresa compra a los pescadores libres y pequeñas cooperativas de Celestún, Isla Arena y otras localidades del estado de Campeche por medio de un sistema de subcontratación (outsourcing). 
Figura 3. Clasificación y distribución de las unidades económicas pesqueras en Isla Arena y Celestún (RBRC), 2016

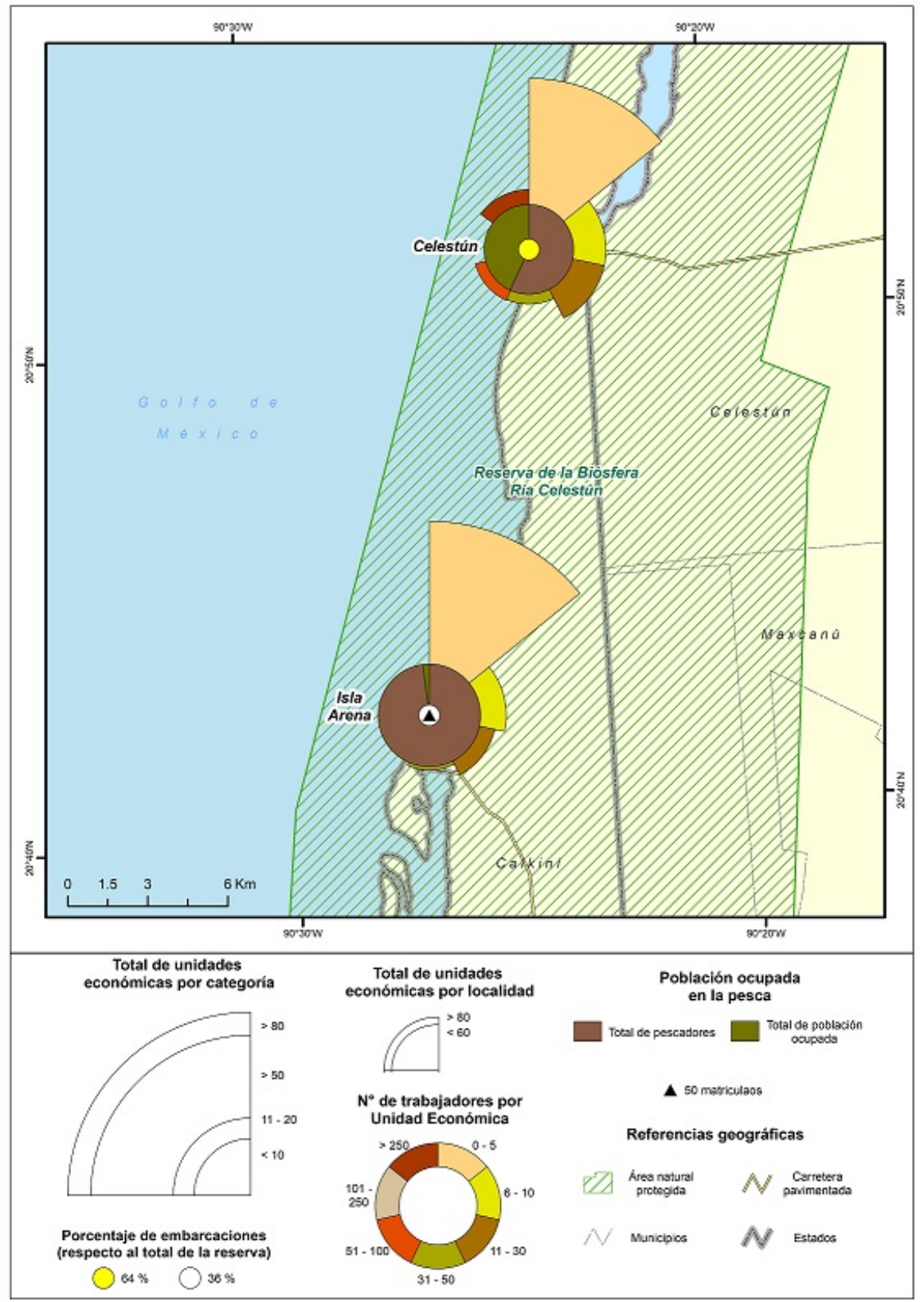

Fuente: Elaborado con base en INEGI, 2016 y datos obtenidos del trabajo de campo. Cartografía, JoséAlberto Garibay-Gómez. 
Una figura curiosa es la de pacotillero quien no es propiamente un pescador, sino un intermediario que compra pescados y mariscos a los pescadores ribereños para después venderlos a las grandes comercializadoras. En Celestún, es común que algunos nuevos pescadores libres provengan de estas prácticas comerciales. La pesca ilegal tiene lugar en ambas localidades, es reconocida en las entrevistas. Los pescadores ribereños denuncian la actividad pesquera sin permiso, la duplicidad de matrículas de las embarcaciones, la utilización de artes prohibidas y la captura de especies protegidas o en época de veda. Una práctica ilegal típica de Celestún la representan los guateros, individuos que aprovechan las características de su embarcación -que mostraremos más adelante- y potencia de su motor, para llegar a zonas donde faenan las embarcaciones mayores de las empresas privadas, para comprar a los pescadores de alta mar parte de su producción. El ribereño la venderá a un precio mayor en tierra y el pescador de alta mar se embolsará un ingreso que dejará de percibir su patrón.

Por tanto, podemos concluir que las dos localidades presentan diferencias en sus organizaciones pesqueras. En Isla Arena existe el matriculado, no en Celestún. De igual manera que en Celestún hay presencia de sociedades anónimas, no en Isla Arena. Si bien en ambos núcleos predominan las personas físicas con permiso de pesca, su dimensión es distinta: en Celestún existe un grupo fuerte de empresarios que no tiene parangón en Isla Arena. Si no contabilizamos las 116 lanchas del permisionario MRS, el promedio de embarcaciones entre las personas físicas celestuneras se eleva 4 lanchas mientras que a los isleños les corresponde sólo una por persona. En lsla Arena, las unidades económicas de mayor tamaño no superan los 50 trabajadores. Celestún dispone de dos unidades económicas que emplean entre 51 y 100 trabajadores y otras dos que superan los 251 (Figura 3). Hemos demostrado así que Celestún posee unidades económicas más grandes y una flota pesquera mayor que Isla Arena (Figura 3).

Como mostraremos, las especies capturadas en la RBRC son variadas pero de entre todas, destacan dos por su repercusión socioeconómica: el pulpo maya y el pepino de mar. La transcendencia de estos dos productos está vinculada a la presión que sobre ellos ha generado la demanda de los mercados internacionales. Por lo que nos interrogamos ¿de qué manera los mercados internacionales han modificado las formas de organización del sector? y ¿qué impactos territoriales han introducido?

\section{Impacto territorial de los mercados internacinales en la actividad pesquera}

Las capturas de los pescadores comerciales ribereños de la RBRC dependen de los permisos de pesca, ahí no existen concesiones pesqueras de mar. Este hecho es significativo pues para optar a un polígono de aprovechamiento pesquero, es necesario presentar unos estudios técnicos y económicos en la solicitud de concesión; para ello, es cardinal un sector fuerte, unido y capitaneado por una unidad económica 
aglutinadora, como es el caso de la zona "Pacífico Norte" de Baja California Sur (Crespo y Jiménez, 2016).

Los permisos de pesca de la RBRC son los de escama (agrupan al jurel, pargo, chac-chi, corvina, mero, rubia, canané, robalo...), tiburón (sobre todo cazón), langosta, caracol (campechanito, blanco, rojo, negro y sacabocado), pulpo (común y rojo o maya) y pepino de mar. La pesca de las dos últimas especies son las de mayor impacto social. En la RBRC, la pesca del pulpo abarca del 1 de agosto al 15 de diciembre, periodo en el que las lanchas de Isla Arena dan trabajo a algo más de 600 pescadores-jornaleros. La captura de este cefalópodo propicia movimientos migratorios temporales de trabajadores de otras localidades costeras ubicadas hacia el sur, como San Francisco de Campeche (a $153 \mathrm{~km}$ de distancia por carretera), Lerma (a $161 \mathrm{~km})$, Seibaplaya (a $186 \mathrm{~km}$ ), Villa Madero (a $205 \mathrm{~km}$ ) y Champotón (a 217 $\mathrm{km})$.

Estos movimientos se relacionan con los buenos precios que en ocasiones alcanza este molusco. 1996 es un año fundamental pues los mercados de Japón, Corea, España e Italia debutan en la compra de volúmenes importantes de pulpo maya. La primera consecuencia fue el incremento del precio que pasó de los $\$ 7 \mathrm{MXN} / \mathrm{kg}$ $\left(\$ 1,31\right.$ USD $\left.^{5}\right)$ de 1994 a los $\$ 24 \mathrm{MXN} / \mathrm{kg}\left(\$ 3,06\right.$ USD) en $1996^{6}$. Al año siguiente, el precio descendió a los $\$ 16 \mathrm{MXN} / \mathrm{kg}$ (\$1,98 USD) por una reducción de la demanda internacional. Sin embargo, en 2002 se alcanzó un precio máximo de $\$ 70 \mathrm{MXN} / \mathrm{kg}$ (\$6,73 USD). El conflicto entre España y Marruecos por el islote Perejil originó que el país ibérico no adquiriera pulpo marroquí y aumentara su demanda sobre el pulpo mexicano. Pero, dos años después, los mercados europeos dejaron de importar pulpo maya porque las plantas de procesamiento no contaban con la certificación sanitaria correspondiente. La aguda crisis económica que vivió Europa en 2008 paralizó la comercialización del pulpo maya: los precios cayeron de nuevo. Tras 5 años de pausa comercializadora, España, Italia, Holanda, Alemania y Dinamarca ${ }^{7}$ volvieron a demandar pulpo rojo. Su precio superó a pie de playa los $100 \mathrm{MXN} / \mathrm{kg}$ (\$7,63 USD). Hoy su importe parece estabilizado al oscilar entre los $\$ 43-48 \mathrm{MXN} / \mathrm{kg}$ en Isla Arena (\$2,5-2,8 USD) y los \$55-60 MXN/kg en Celestún (\$3,2-3,5 USD).

La primera consecuencia de la irrupción de los mercados internacionales en la RBRC fue cumplir con la regulación de higiene en el procesamiento de los productos marinos y la modernización de las plantas congeladoras. También se invirtió en las embarcaciones menores y en los equipos de conservación y traslado del producto. Conseguir la certificación sanitaria de exportación fue fundamental para asegurar buenos precios pero la demanda internacional encareció la venta nacional.

\footnotetext{
${ }^{5}$ Todas las conversiones al dólar están referenciadas al valor histórico del cambio.

${ }^{6} \mathrm{http} / /$ www.gbcbiotech.com/genomicaypesca/documentos/moluscos/pulpo/Pulpo\%20Region\%20IV.pdf [Consulta: 10 octubre 2016].

http://www.elfinanciero.com.mx/archivo/regresa-pulpo-maya-a-europa.html [Consulta: 10 octubre 2016].
} 
En cuanto al pepino de mar, sin duda la especie más conflictiva, la SAGARPA reconoce que "el recurso pepino de mar localizado en las aguas de jurisdicción federal frente al litoral de la Península de Yucatán es de interés para los pescadores locales debido a su alto valor comercial en el mercado internacional"8. En los últimos años, la SAGARPA ha establecido diversos períodos de veda temporal sobre las cuatro especies de pepino de mar para su recuperación y desde 2012, está vedado permanentemente en el estado de Campeche. Sin embargo, en el de Yucatán a partir del 2013, las autoridades han concedido en promedio 17 días para la recolección del pepino de mar café, entre los meses de abril y mayo, con una cuota media de unas $640 \mathrm{t}$.

Ahora, los isleños han asumido que no deben pescarlo, argumentan razones de tipo ecológico: "el mar huele mal" afirman algunos pescadores (el pepino filtra la materia orgánica en proceso de descomposición del fondo del mar). Pero en 2010 un grupo de 20 pescadores de Isla Arena se manifestó frente al Palacio de Gobierno de Campeche para solicitar permisos de pepino'; al año siguiente, hubo fuertes protestas producidas por el disconforme reparto de los permisos ${ }^{10}$ y fue la última temporada en la que los isleños lo capturaron: participaron 90 embarcaciones que durante 44 días obtuvieron 420 t. Desde el 2012, las tensiones que afloran se deben a su pesca ilegal.

En Celestún, durante las temporadas 2013 y 2014, el precio del pepino de mar fresco con tripas osciló entre los $\$ 22 \mathrm{MXN} / \mathrm{Kg}$ (\$1,8 USD) y los $\$ 25 \mathrm{MXN} / \mathrm{Kg}$ (\$2,06 USD), eviscerado a $\$ 30 \mathrm{MXN} / \mathrm{Kg}$ (\$2,47 USD) y sancochado a $\$ 300 \mathrm{MXN} / \mathrm{Kg}$ (\$24,75 USD). Su valor se incrementa notablemente en el mercado ilegal, donde hoy alcanza los $2.500 \mathrm{MXN} / \mathrm{Kg}$ (\$145 USD). En Asia, su importe oscila entre los 150 y $500 \mathrm{USD} / \mathrm{Kg}$. Estos precios superan el de algunas drogas ilícitas, como la marihuana, por lo que no es de extrañar que la marina mexicana haya desplegado parte de su flota en el Caribe con fines disuasorios o para atrapar a los ilegales. Las autoridades militares aseguran que la RBRC es el epicentro de esta conflictividad en las aguas de la península de Yucatán. La captura ilegal del pepino de mar se ha convertido en la principal industria ilícita en los estados de Yucatán y Campeche (datos oficiales de la Secretaría Nacional de la Seguridad Pública ${ }^{11}$ ). Lo que ha alterado las tradicionales relaciones entre los pescadores de Isla Arena y Celestún, hasta el punto de que algunos pescadores han sugerido la creación de grupos de autodefensa. Los isleños acusan a las mafias celestuneras de "lucrarse con la piratería en sus aguas" donde está vedado permanentemente ${ }^{12}$. También hay

\footnotetext{
${ }^{8} \mathrm{http}: / /$ dof.gob.mx/nota_detalle.php?codigo=5440953\&fecha=10/06/2016 [Consulta: 11 octubre 2016].

${ }^{9} \mathrm{http}: / / \mathrm{www}$. comunicacampeche.com/Php/noticiacomlocal.php?id=63952 [Consulta: 11 octubre 2016].

$10 \mathrm{http} / /$ www.poresto.net/ver_nota.php?zona=qroo\&idSeccion $=31 \&$ idTitulo $=149424$ [Consulta: 11 octubre 2016].

11 http://www.milenio.com/estados/Campeche-Yucatan-peor-crisis-pepino-pescadores-inseguridadplagio-extorsion_0_380361995.html [Consulta: 11 octubre 2016].

$12 \mathrm{http} / / /$ www.comunicacampeche.com.mx/Php/noticiacomlocal.php?id=142674 [Consulta: 11 octubre 2016].
} 
movilizaciones en Celestún, ciertos grupos pesqueros solicitan mayor vigilancia sobre los pescadores del estado de Campeche (procedentes de Champotón, Seybaplaya y Sabancuy) a quienes acusan de practicar pesca ilegal de pepino de mar y pulpo frente a sus costas.

Figura 4. Congeladoras certificadas por localidad en los estados de Campeche y Yucatán, 2016.

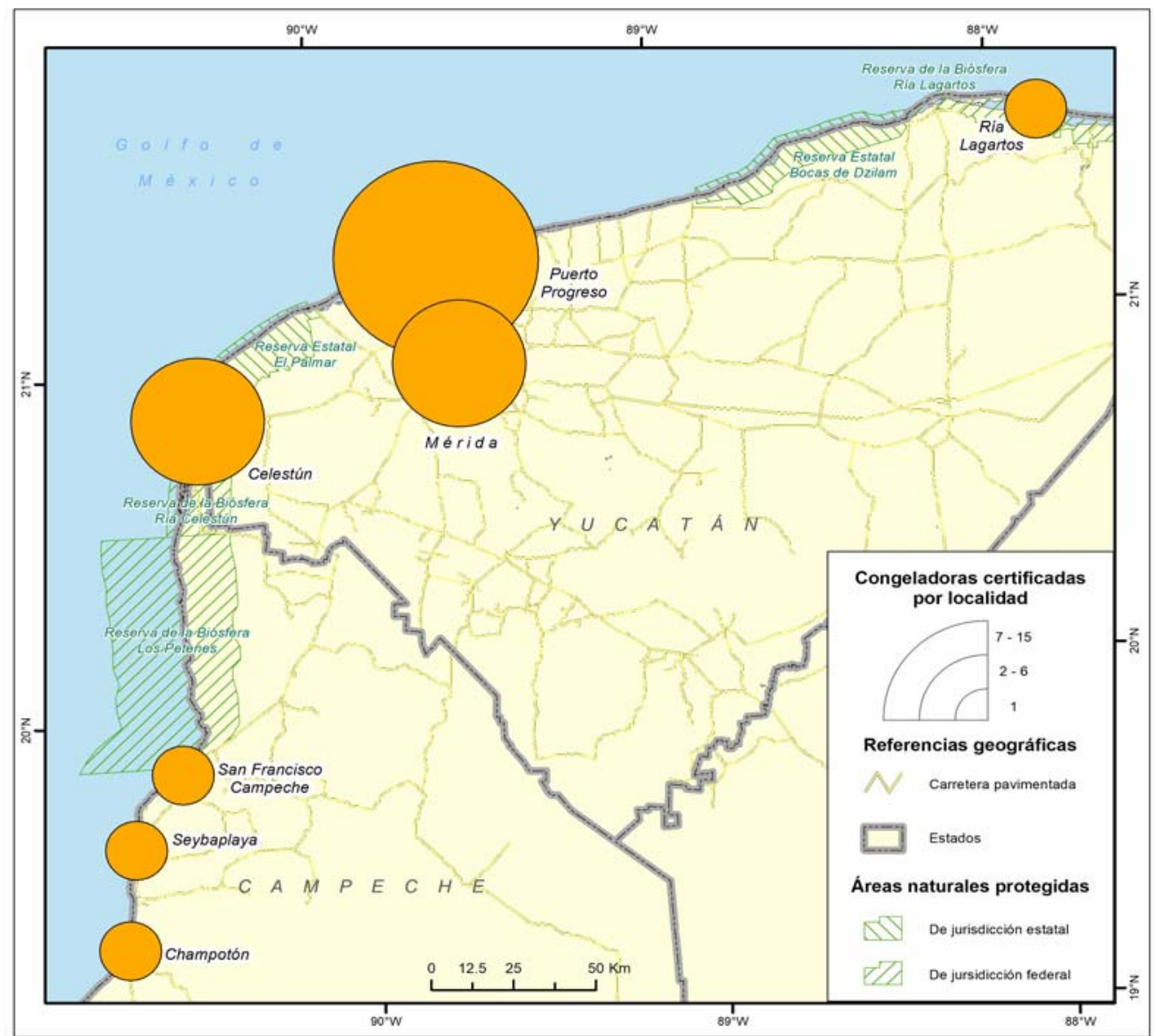

Fuente: Elaborado con datos de la CONAPESCA y procedentes del trabajo de campo, 2016. Cartografía, José-Alberto Garibay-Gómez.

La recolecta del caracol también crea tensiones sociales y posee impacto territorial. Entre los meses de marzo y julio, los permisionarios de Isla Arena han estado contratando a buzos experimentados de Seibaplaya y Champotón para su captura, lo que explica el malestar entre pescadores isleños. En marzo de 2016 se reunieron los representantes del sector haliéutico y los permisionarios se comprometieron a 
contratar pescadores locales y el alcalde a garantizar "mano de obra seria y responsable"13.

Figura 5. Capturas y flujos comerciales nacionales de productos pesqueros de Isla Arena y Celestún (RBRC), 2015

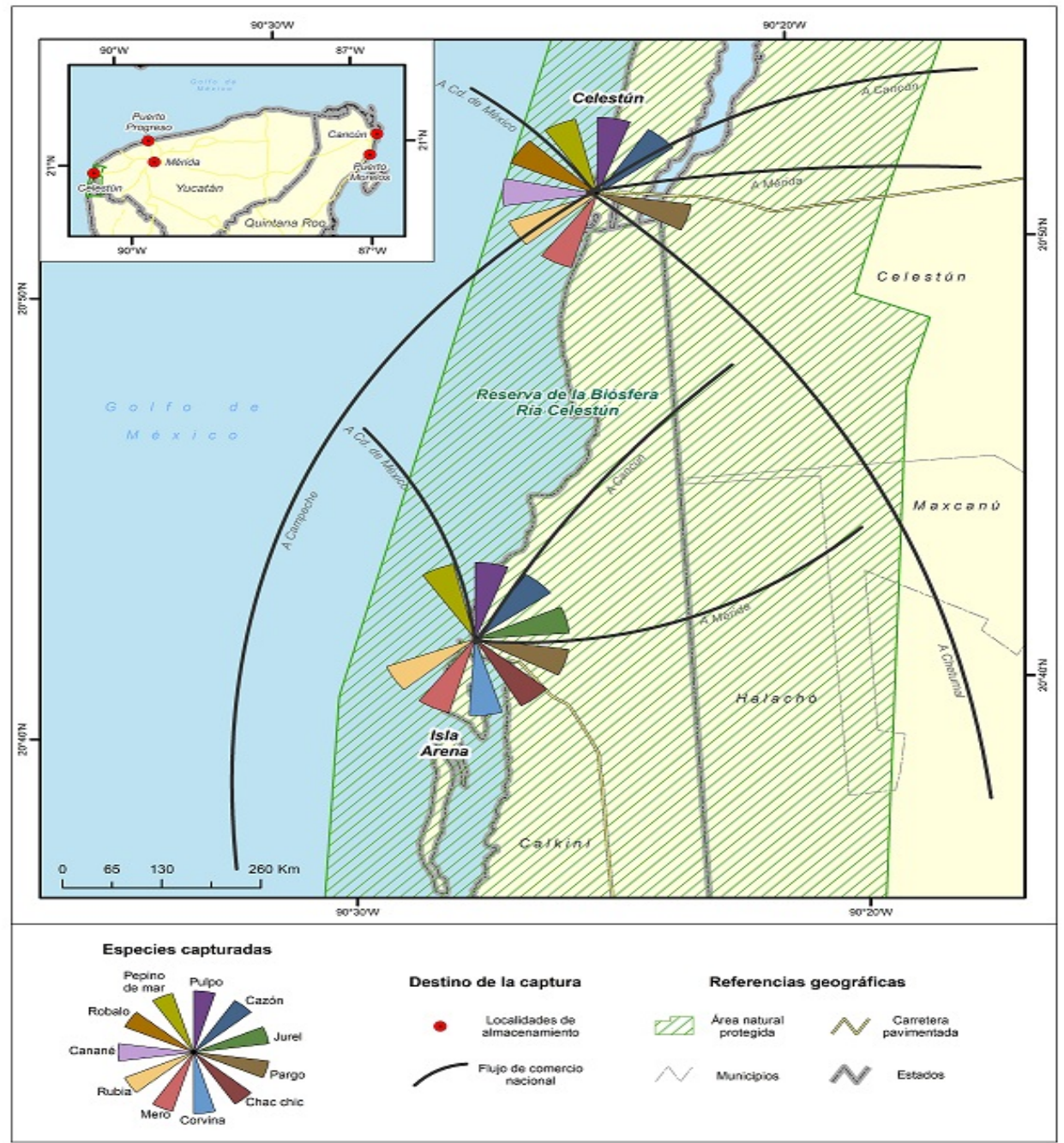

Fuente: Elaborado con base en CONANP, 2016 y datos obtenidos del trabajo de campo. Cartografía, José-Alberto Garibay-Gómez.

${ }^{13} \mathrm{http}: / /$ www.reporte24.com.mx/campeche/acuerdos-para-evitar-depredacion-de-recursos-pesqueros-enisla-arena/ [Consulta: 10 octubre 2016]. 
En cuanto a la comercialización, la producción pesquera en Isla Arena suele venderse en playa a los intermediarios (coyotes) que, o bien la desplazan a Celestún donde se almacena (convirtiéndose en un espacio de acopio intermedio) o bien la trasladan directamente a los grandes centros de distribución: las congeladoras de Puerto Progreso y Mérida (Figura 4). De allí parte a dos mercados: el nacional y el internacional. El primero, el menos importante, tiene sus centros en Mérida, Cancún y Ciudad de México (Figura 5). El segundo, el más lucrativo, en EEUU (Miami y Luisiana; consumidores del boquinete y la corvina), Europa (España, Italia, Holanda, Alemania y Dinamarca; fundamentalmente demandan el pulpo maya) y Asia (Corea, Japón, China y Hong Kong; cuando se abre la veda, suelen comprar el pepino de mar; Japón también adquiere frecuentemente pulpo maya; Figura 6). Tres congeladoras certificadas del estado de Campeche exportan.

En Celestún, Hulkin dispone de permisos de escama, pulpo, pepino y tiburón, la empresa también está certificada por la Comisión Federal para la Protección contra Riesgos Sanitarios (COFEPRIS) para la venta internacional y exporta su producción de pescado fresco vía aérea (desde los aeropuertos de Mérida y Cancún) y congelado, vía marítima (desde Puerto Progreso y Puerto Morelos). La pesca de pepino de mar, cuando se autoriza, se envía íntegramente a Hong-Kong, aunque suele haber intermediarios en Los Ángeles (EEUU), que compran el pepino y luego lo mandan al mercado asiático desde tierras estadounidenses. El destino del pescado fresco suele ser Miami y del congelado Nueva York y la ciudad de Panamá. El pulpo maya se exporta esencialmente a España y en ocasiones a Japón (Figura 6). El peso de Hulkin es tan fuerte en la economía de la localidad que su socio mexicano se ha alzado con la presidencia municipal.

Aunque, según los pescadores de Isla Arena, haya pesca ilegal, por lo general se percibe una conciencia del cuidado de los recursos marinos pues la mayor parte de la población vive de ellos. Los pescadores isleños han conseguido que los de Celestún y otras localidades del estado de Campeche no practiquen la actividad haliéutica a unas $10 \mathrm{mn}(18,52 \mathrm{~km})$ frente a las costas de su localidad (Figura 7). Esta distribución de los espacios de aprovechamiento, de naturaleza sociocultural, se tensiona reiteradamente por el excelente precio de ciertos productos. Precisamente, los pescadores ribereños de Isla Arena no suelen separarse más de $10 \mathrm{mn}$ de la línea de costa cuando capturan la corvina pinta, el jurel común o blanco, el pargo, el chac-chi, el pulpo maya, entre otros. Las distancias aumentan hasta las $40 \mathrm{mn}$ de la línea de costa (algo más de $74 \mathrm{~km}$ ) en la pesca del cazón, el mero y la rubia. Consideremos que la plataforma continental es excepcionalmente ancha en esta zona occidental de la península de Yucatán, pues llega a alcanzar los $180 \mathrm{~km}$ (Lugo-Hubp, 1992). Las lanchas suelen utilizar motores fueraborda de $60 \mathrm{hp}$, GPS, radios (banda civil) y neveras; pocas disponen de sondas. 
Figura 6. Flujos comerciales internacionales de productos pesqueros de la RBRC, 2016

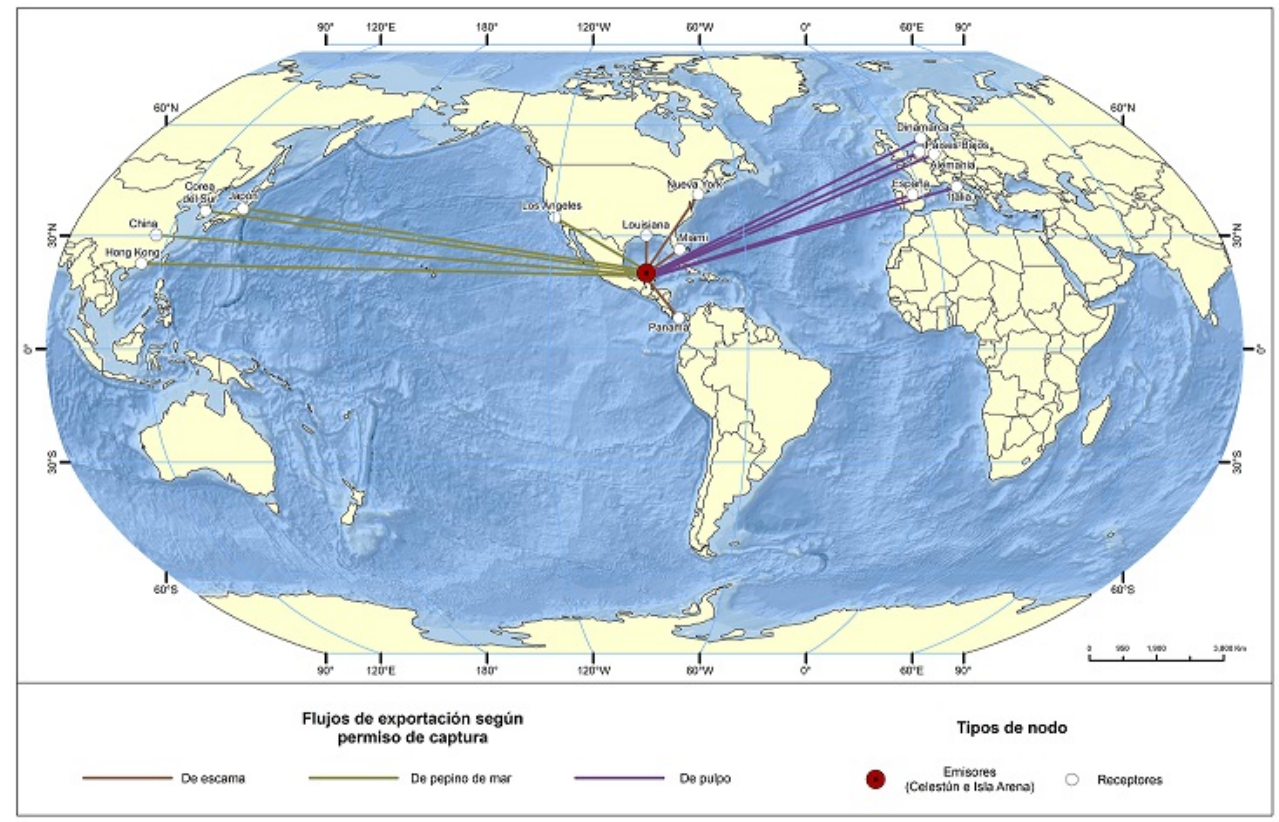

Fuente: Elaborado con base en el trabajo de campo, 2016. Cartografía, José-Alberto Garibay-Gómez.

En Celestún, las embarcaciones disponen de neveras para la conservación del producto, GPS, radios, sondas y chip de localización. Predominan los motores fueraborda de $85 \mathrm{hp}$, lo que permite a los pescadores alejarse hasta los $100 \mathrm{~km}$ al interior del mar. Para hacer frente a las dificultades que ofrece el mar en aquellas distancias y al aumento de la capacidad de pesca, las lanchas han elevado llamativamente su casco (Figura 8). Esta localidad también se ha transformado en un centro de almacenaje y distribución de pescado, por lo que algunos habitantes han invertido en nuevos espacios de conservación/almacenaje y han creado una red de distribución bien articulada que va más allá de las fronteras nacionales. La profesionalización, tecnificación y aumento de la producción pesquera han hecho que algunas organizaciones vinculadas al sector haliéutico demanden un mayor control de la actividad pesquera, incluso han solicitado la creación de un espacio de no-pesca, denominado "zona de refugio pesquero" (Figura 7). 
Figura 7. Alcance geográfico de los espacios de pesca en la RBRC, 2016.

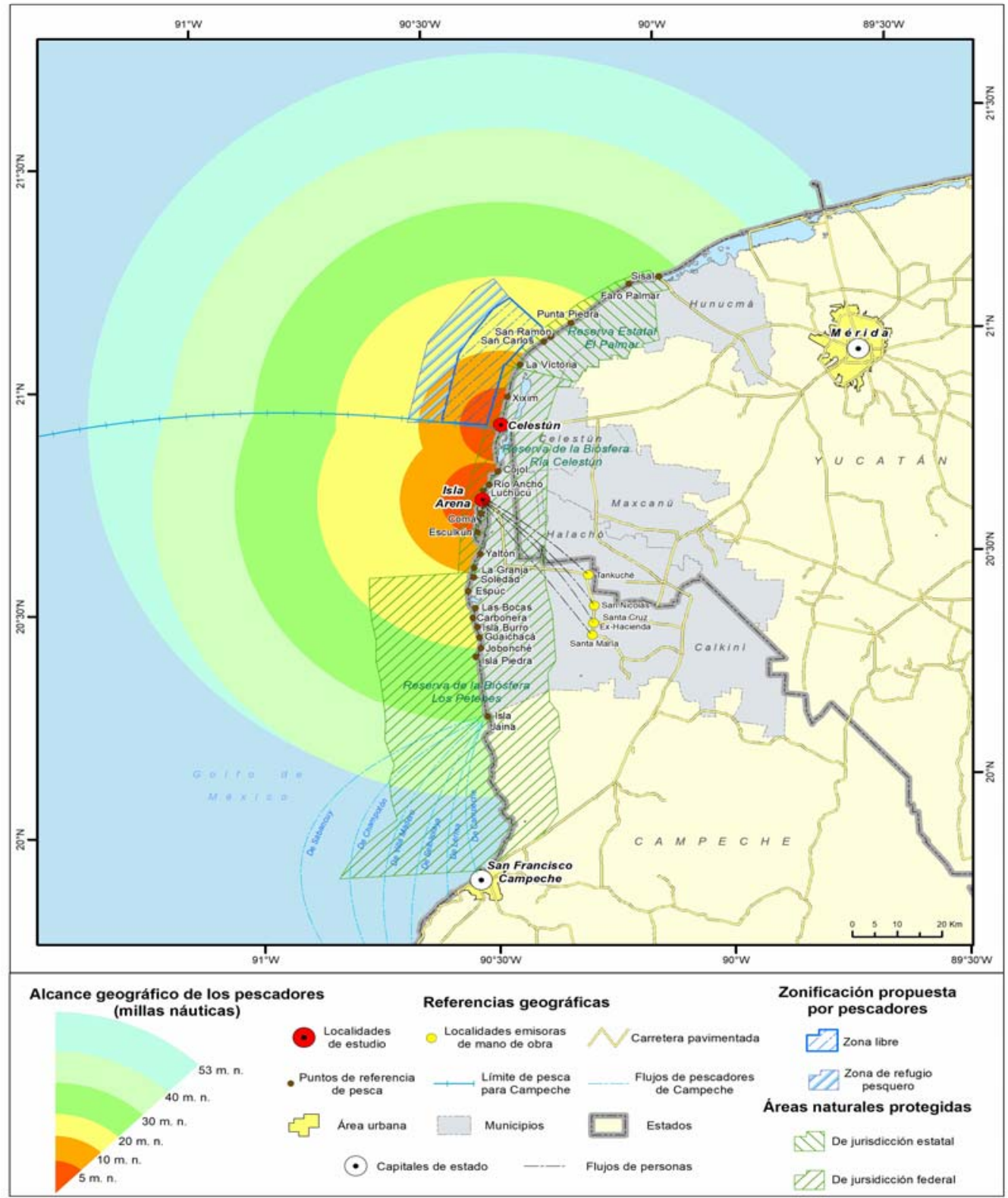

Fuente: Elaborado con base en el trabajo de campo, 2016. Cartografía, José-Alberto Garibay-Gómez. 
Figura 8. Detalle de embarcaciones en el puerto de abrigo de Celestún, marzo 2016.

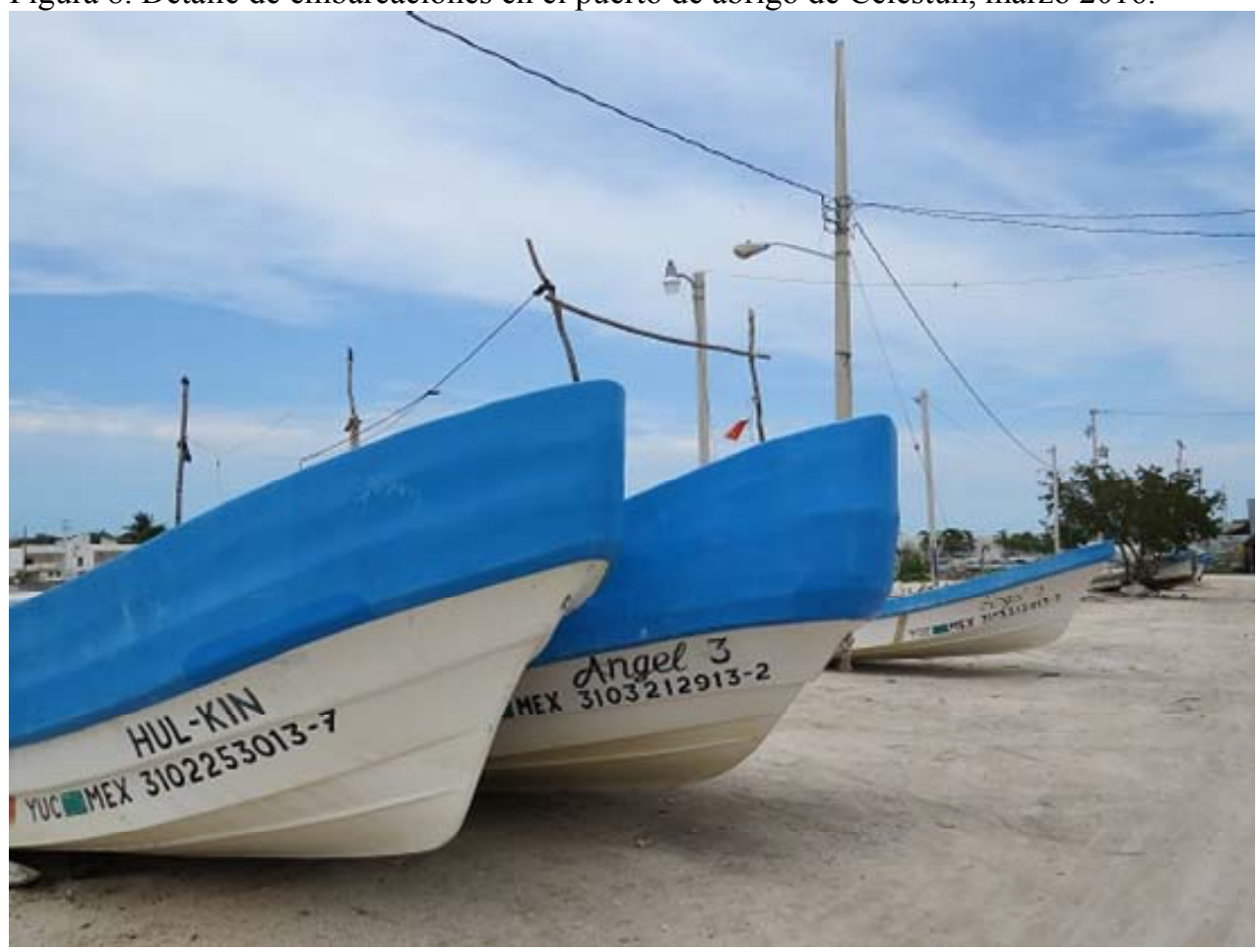

Fuente: Archivo de campo Crespo-Guerrero y Jiménez-Pelcastre.

Así pues, la presión de los mercados internacionales sobre los recursos del mar ha generado modificaciones en las prácticas tradicionales de la pesca. Lo que ha impactado territorialmente y conducido a fuertes tensiones sociales. Todo ello ha alterado las relaciones socioculturales establecidas entre los pescadores de la RBRC y otros de la región. La reserva, bajo su dimensión actual, no ofrece soluciones y parte del sector haliéutico propone nuevas zonas de conservación e incluso de preservación. La categoría "Reserva de la biosfera" dispone de los instrumentos adecuados para ordenar y gestionar estas presiones, pero es necesaria una revisión profunda de lo que hoy es el área natural protegida.

\section{Conclusiones}

La introducción de las localidades de Isla Arena y Celestún en las redes internacionales de compra-venta de productos marinos ha propiciado la modernización de la flota pesquera, nuevas infraestructuras que aseguran una mejor calidad e higiene del procesamiento, la llegada de inversión extranjera y movimientos 
pendulares de mano de obra en las temporadas de mayor captura. Sin embargo, ha modificado el tradicional reparto de los espacios de pesca, con lo que se han tensionado las relaciones entre ambas localidades. Mientras que los pescadores de Isla Arena han mantenido prácticas menos extractivas, los de Celestún han optado por soluciones técnicas para aumentar su producción que, unidas a las actividades ilegales, provocan una importante presión sobre el área y obligan a los celestuneros a salir cada vez más lejos a pescar.

Paralelamente, se alzan voces desde el propio sector que proponen la creación de zonas de no-pesca. La posible ampliación del ANP hacia las aguas contiguas puede servir para armonizar estos procesos de cambio impulsados desde la globalización a fin de asegurar la reproducción de las especies. Un efecto inmediato sería también la reducción de costes al disminuir la distancia entre los caladeros y los puertos de abrigo. He aquí una oportunidad para el gobierno mexicano de aumentar la zona marítima protegida de la RBRC pues contribuiría, no sólo a regular la actividad pesquera por medio de las herramientas que ofrecen las ANP, sino también a responder a una demanda popular. Además, el incremento de la zona marítima protegida se enlazaría perfectamente con las Metas de Aichi ya que entre ellas se encuentra la protección del $10 \%$ de las zonas marinas y costeras (Objetivo estratégico $\mathrm{C}$, meta 11). Asegurar el futuro de la actividad pesquera de la RBRC implica regularla eficientemente con el fin de conservar los recursos del mar sin comprometer el desarrollo socioeconómico de sus poblaciones. Esta responsabilidad no es exclusiva de las instituciones públicas, sino también del propio sector, ya sea de índole social o privado.

De la misma manera que el poder público debe ser el primero en velar por hacer cumplir la ley -lo que llevaría a actualizar regularmente el PM de una manera participativa-, el sector pesquero debe implicarse en la búsqueda de fórmulas que aseguren los mercados existentes y abran otros, mejoren las condiciones laborales, aumenten los precios a pie de playa y ofrezcan oportunidades de promoción, salvaguardando eficazmente los recursos que ofrece el golfo de México. Para ello es necesaria la creación de una mesa profesional que represente fielmente al sector desde su heterogeneidad. Una mesa que pudiera derivar en una coalición "legal" -ya fuese federación, confederación u otra- que la dote de capacidad de liderazgo y promoción de iniciativas como la certificación de pesquerías sostenibles. Eso obligaría a implementar un sistema de gestión de los recursos más participativo para asegurar su durabilidad. Hoy, las tensiones que se producen en el seno de la actividad económica, las dificultades de la reserva para participar en el ordenamiento de las pesquerías y los problemas que presentan los ecosistemas marinos de la zona, son una realidad, consecuencia también del poco o nulo interés que muestran ciertos mercados internacionales por los impactos ambientales, territoriales y socioeconómicos, con el fin de satisfacer un consumo que ignora por completo los principios de la sostenibilidad. 


\section{Referencias bibliográficas}

Araque, E. y Crespo, J.M. (2009): Conservation versus développement? une nouvelle situation conflictuelle dans les parcs naturels andalous. En Laslaz, Lionel et al. (cood.). Espaces protégés, acceptation sociale et conflits environnementaux, Cahiers de Géographie. Colection EDYTEM, 10. Chambery: Université Savoie.

Carabias, J. y Cadena, R. (2003): Capacidades necesarias para el manejo de áreas protegidas en América Latina y el Caribe. Virginia: The Nature Conservancy: Arlington.

Chenaut, V. (1985): Los pescadores de la península de Yucatán. En Cuadernos de la Casa Chata, 12. Serie los pescadores de México. Ed. Centro de Investigaciones y Estudios Superiores de Antropología Social: México.

CONABIO, Comisión Nacional para el Conocimiento y Uso de la Biodiversidad (2008): Sitios prioritarios marinos para la conservación de la biodiversidad. Mapa a escala 1:4.000.000. Comisión Nacional de Áreas Naturales Protegidas, The Nature Conservancy Programa México. Pronatura.

CONANP, Comisión Nacional de Áreas Naturales Protegidas (2016): Áreas Naturales Protegidas Decretadas. Comisión Nacional de Áreas Naturales Protegidas: México. $<$ http://www.gob.mx/conanp/acciones-y-programas/areas-naturales-protegidas-decretadas> [Consulta: 16 septiembre 2016].

Crespo, J.M. y Jiménez, A. (2016): Organización del sector pesquero comercial ribereño en la Reserva de la Biosfera El Vizcaíno (México). Revista Geográfica Venezolana, 57(2), en prensa.

Crespo, J.M. y Peyroti, G. (2016): Las áreas naturales protegidas de Córdoba (Argentina): desarrollo normativo y ausencia de gestión territorial. Cuadernos Geográficos, 55(1), 3358.

$<$ http://revistaseug.ugr.es/index.php/cuadgeo/article/view/3191> [Consulta: 10 septiembre 2016].

DOF, Diario Oficial de la Federación (2007): Ley de pesca y acuacultura sustentables. 24 de julio de 2007.

$<$ http://www.semar.gob.mx/marco_normativo/ley_general_pesca.pdf $>$ [Consulta: 10 septiembre 2016].

DOF, Diario Oficial de la Federación (2013). Acuerdo mediante el cual se acuerda la actualización de la Carta Nacional Acuícola. 9 de septiembre de 2013.

$<$ http://dof.gob.mx/nota_detalle.php?codigo $=5313326 \&$ fecha $=09 / 09 / 2013>\quad$ [Consulta: 10 septiembre 2016].

DOF, Diario Oficial de la Federación (2014). Reglamento de la Ley General del Equilibrio Ecológico y la Protección al Ambiente en materia de áreas naturales protegidas. 21 de mayo de 2014.

$<$ http://www.diputados.gob.mx/LeyesBiblio/regley/Reg_LGEEPA_ANP.pdf $>$ [Consulta: 10 septiembre 2016].

DOF, Diario Oficial de la Federación (2016). Ley General de Equilibrio Ecológico y Protección del Ambiente. 13 de mayo de 2016. 
$<$ http://www.diputados.gob.mx/LeyesBiblio/pdf/148_130516.pdf $>$ [Consulta: 13 septiembre 2016].

Europarc-España (2008): Planificar para gestionar los espacios naturales protegidos. Serie manuales EUROPARC-España. Plan de acción para los espacios naturales protegidos del Estado español. Editado por Fundación Interuniversitaria Fernando González Bernáldez para los espacios naturales: Pozuelo de Alarcón.

FAO, Organización de las Naciones Unidas para la Agricultura y la Alimentación (2010): Estudio social de la pesca en México: diagnóstico sobre la problemática social de los pescadores, su entorno y su visión sobre las posibles soluciones a los problemas que afectan la pesca. Resultado y recomendaciones del Proyecto. Fondo Fideicomiso Mexicano. México. FAO: Roma. $\quad<$ http://coin.fao.org/coinstatic/cms/media/6/12886502436680/informe_final_estudio_social_de_la_pesca_en_mxic o.pdf> [Consulta: 19 septiembre 2016].

FAO, Organización de las Naciones Unidas para la Agricultura y la Alimentación (2011): Caracterización y definición de la pesca en pequeña escala. Documento de debate: hacia unas directrices voluntarias para asegurar la pesca sostenible en pequeña escala. FAO: Roma.

FAO, Organización de las Naciones Unidas para la Agricultura y la Alimentación (2016a): El estado mundial de la pesca y la acuicultura. <http://www.fao.org/3/a-i5555s.pdf $>$ [Consulta: 19 septiembre 2016].

FAO, Organización de las Naciones Unidas para la Agricultura y la Alimentación (2016b): Visión general de la legislación acuícola nacional México. $<$ http://www.fao.org/fishery/legalframework/nalo_mexico/es $>$ [Consulta: 17 septiembre 2016].

Fraga, J.E. (2004): Pesquerías y movimientos de población en la costa de Yucatán. En Resumen de la I Conferencia de Pesquerías Costeras en América Latina y el Caribe. COASTFISH. Yucatán. Mérida.

Fraga, J.E. (2009): Atrapados en un torbellino de cambios. Revista Samudra, 52, 26-32.

$<$ http://old.icsf.net/icsf2006/uploads/publications/samudra/pdf/spanish/issue_52/art05.pdf $>$ [Consulta: 05 marzo 2016].

Gutiérrez, C. (2014): El contexto de vulnerabilidad social de pescadores ribereños en la península de Yucatán. Sociedad y Ambiente, 1(5), 25-47. $<$ http://revistas.ecosur.mx/sociedadyambiente/index.php/sya/article/view/1549>

Hockings, M.; Stolton, S. y D., Nigel (2000): Evaluación de la eficacia. Marco de referencia para la evaluación de la gestión de las áreas protegidas. Series sobre mejores prácticas en áreas protegidas, núm. 6 UICN, Gland y Cambridge.

INEGI, Instituto Nacional de Estadística (2010). XIII Censo de Población y Vivienda. INEGI: Aguascalientes.

INEGI, Instituto Nacional de Estadística (2016): Directorio Estadístico Nacional de Unidades Económicas. INEGI: Aguascalientes. <beta.inegi.org.mx/app/mapa/denue/default.aspx> [Consulta: 17 septiembre 2016].

Lugo, J.; Aceves, J.F. y Espinosa, R. (1992). Rasgos geomorfológicos mayores de la península de Yucatán. Revista mexicana de ciencias geológicas, 10(2), 143-150. $<$ http://satori.geociencias.unam.mx/10-2/(6)Lugo.pdf> [Consulta: 03 abril 2016]. 
Mexicano, G.; Liceaga, M.A. y Salas, S. (2009): Uso de sistemas de información geográfica en pesquerías: la pesca en Yucatán, al sur del Golfo de México. Universidad y ciencia, 25(1), 23-38.

$<\mathrm{http}: / /$ www.universidadyciencia.ujat.mx/index.php?ID=24\&art=405> [Consulta: 25 febrero 2016].

Morales, A. (2015): Conflictos ambientales vinculados a la pesquería de pulpo en Celestún, Yucatán. Tesis de licenciatura. Facultad de Filosofía y Letras. Colegio de Geografía. Universidad Nacional Autónoma de México. Ciudad de México.

Rife, A.N.; Erisman, B.; Sánchez, A. y Aburto, O. (2013): When good intentions are not enough... Insights on networks of "paper park" marine protected areas. Conservation Letters, 6, 200-212.

DOI: https://doi.org/10.1111/j.1755-263x.2012.00303.x

[Consulta: 05 marzo 2016].

Robles, R. (2005): Apropiación de recursos naturales y relaciones sociales en la Reserva de la Biosfera Ría Calestún, Yucatán. Tesis de maestría. Departamento de Ecología Humana, Centro de Investigación y de Estudios Avanzados del Instituto Politécnico Nacional (CINVESTAV). Unidad de Mérida. Mérida.

Rodríguez, R. y Melville, R. (1984). Los pescadores de la laguna de Términos. SEP Cultura, Centro de Investigaciones y Estudios Superiores en Antropología Social.

Sánchez, M.T.; Fraga, J.E. y Maas, R. (1999): Pesca. Atlas de Procesos territoriales de Yucatán. Universidad Autónoma de Yucatán. Facultad de Arquitectura, 91-106. Mérida.

SAGARPA, Secretaría de Agricultura, Ganadería, Desarrollo Rural, Pesca y Alimentación (2013): Anuario estadístico de acuacultura y pesca 2013 de la Comisión Nacional de Acuacultura y Pesca. Comisión Nacional de Acuacultura y Pesca: México. $<$ https:/www.gob.mx/conapesca/documentos/anuario-estadistico-de-acuacultura-y-pesca> [Consulta: 19 septiembre 2016].

SEMARNAT, Secretaría de Medio Ambiente y Recursos Naturales (2002): Programa de Manejo Reserva de la Biosfera Ría Celestún. Comisión Nacional de Áreas Naturales Protegidas. Dirección Jurídica: México.

SENASICA, Servicio Nacional De Sanidad, Inocuidad Y Calidad Agroalimentaria (2016): Padrón de Permisionarios adheridos al programa de Prácticas de Manejo a Bordo de Embarcaciones Menores. Servicio Nacional Sanidad, Inocuidad y Calidad Agroalimentaria. Dirección General de Inocuidad Agroalimentaria, Acuícola y Pesquera: México.

$<$ https://www.gob.mx/cms/uploads/attachment/file/120916/CAMPECHE.pdf $>$ [Consulta: 10 octubre 2016].

Secretaría del Convenio sobre la Diversidad Biológica (2010): Plan Estratégico para la Diversidad Biológica 2011-2020 y las Metas de Aichi. Programa de Naciones Unidas para el Medio Ambiente: Quebec.

$<$ https://www.cbd.int/doc/strategic-plan/2011-2020/Aichi-Targets-ES.pdf $>$ [Consulta: 16 septiembre 2016]. 
Soares, D. y Vargas, S. (2011): Capitales comunitarios y vulnerabilidad social frente al cambio climático en un municipio de Yucatán. Trayectorias, 2012, 14 (33-34), 51-75. $<$ http://trayectorias.uanl.mx/33y34/pdf/3_soares_vargas.pdf $>$ [Consulta: 05 marzo 2016].

Soares, D.; Murillo, D.; Romero, R., et al. (2014): Amenazas y vulnerabilidades: las dos caras de los desastres en Celestún, Yucatán. Desacatos, 44, 159-177.

$<$ http://desacatos.ciesas.edu.mx/index.php/Desacatos/article/view/454/382> [Consulta: 03 abril 2016].

Strauss, A. y Corbin, J. (2002): Bases de la investigación cualitativa. Técnicas y procedimientos para desarrollar la teoría fundamentada. Editorial Universitaria de Antioquía. Facultad de Enfermería de la Universidad de Antioquía: Antioquía. 340 p.

Uc, M. (2007): Estrategias de vida en hogares costeros, estudio de caso en Celestún, Yucatán. Tesis de Maestría. Departamento de Ecología Humana, Investigación y de Estudios Avanzados del Instituto Politécnico Nacional (CINVESTAV), Unidad de Mérida. Yucatán. Mérida.

$<$ http://www.ecologiahumana.mda.cinvestav.mx/images/egresados/TesisUcEspadas.pdf $>$ [Consulta: 03 abril 2016].

Viga, M.D. (2014): Conflictos entre actores por el manejo y conservación de los recursos naturales en la costa de Yucatán. En Euán, J.I.; García, A.; Liceaga, M.A. y Mungía, A. (eds.). La costa del Estado de Yucatán un espacio en reflexión sobre la relación sociedadnaturaleza, en el contexto de su ordenamiento territorial. Comisión Nacional para el Conocimiento y Uso de la Biodiversidad (Conabio). Ciudad de México.

Villerías, S. y Sánchez, A. (2010). Perspectiva territorial de la pesca en la Costa Chica de Guerrero. Investigaciones Geográficas, Boletín del Instituto de Geografía, 71, 43-56.

DOI: http://dx.doi.org/10.14350/rig.18089 [Consulta: 03 abril 2016]. 